\title{
A Numerical Study of Anti-Vortex Film Cooling Designs at High Blowing Ratio
}

James D. Heidmann

Glenn Research Center, Cleveland, Ohio 


\section{NASA STI Program . . . in Profile}

Since its founding, NASA has been dedicated to the advancement of aeronautics and space science. The NASA Scientific and Technical Information (STI) program plays a key part in helping NASA maintain this important role.

The NASA STI Program operates under the auspices of the Agency Chief Information Officer. It collects, organizes, provides for archiving, and disseminates NASA's STI. The NASA STI program provides access to the NASA Aeronautics and Space Database and its public interface, the NASA Technical Reports Server, thus providing one of the largest collections of aeronautical and space science STI in the world. Results are published in both non-NASA channels and by NASA in the NASA STI Report Series, which includes the following report types:

- TECHNICAL PUBLICATION. Reports of completed research or a major significant phase of research that present the results of NASA programs and include extensive data or theoretical analysis. Includes compilations of significant scientific and technical data and information deemed to be of continuing reference value. NASA counterpart of peer-reviewed formal professional papers but has less stringent limitations on manuscript length and extent of graphic presentations.

- TECHNICAL MEMORANDUM. Scientific and technical findings that are preliminary or of specialized interest, e.g., quick release reports, working papers, and bibliographies that contain minimal annotation. Does not contain extensive analysis.

- CONTRACTOR REPORT. Scientific and technical findings by NASA-sponsored contractors and grantees.

- CONFERENCE PUBLICATION. Collected papers from scientific and technical conferences, symposia, seminars, or other meetings sponsored or cosponsored by NASA.

- SPECIAL PUBLICATION. Scientific, technical, or historical information from NASA programs, projects, and missions, often concerned with subjects having substantial public interest.

- TECHNICAL TRANSLATION. Englishlanguage translations of foreign scientific and technical material pertinent to NASA's mission.

Specialized services also include creating custom thesauri, building customized databases, organizing and publishing research results.

For more information about the NASA STI program, see the following:

- Access the NASA STI program home page at http://www.sti.nasa.gov

- E-mail your question via the Internet to help@ sti.nasa.gov

- Fax your question to the NASA STI Help Desk at 301-621-0134

- Telephone the NASA STI Help Desk at 301-621-0390

- Write to: NASA Center for AeroSpace Information (CASI) 7115 Standard Drive Hanover, MD 21076-1320 


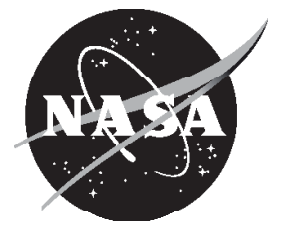

\section{A Numerical Study of Anti-Vortex Film Cooling Designs at High Blowing Ratio}

James D. Heidmann

Glenn Research Center, Cleveland, Ohio

Prepared for the

Turbo Expo 2008 Gas Turbine Technical Congress and Exposition sponsored by the American Society of Mechanical Engineers

Berlin, Germany, June 9-13, 2008

National Aeronautics and

Space Administration

Glenn Research Center

Cleveland, Ohio 44135 
Trade names and trademarks are used in this report for identification only. Their usage does not constitute an official endorsement, either expressed or implied, by the National Aeronautics and Space Administration.

This work was sponsored by the Fundamental Aeronautics Program at the NASA Glenn Research Center.

Level of Review: This material has been technically reviewed by technical management.

Available from

NASA Center for Aerospace Information 7115 Standard Drive

Hanover, MD 21076-1320
National Technical Information Service 5285 Port Royal Road Springfield, VA 22161

Available electronically at http://gltrs.grc.nasa.gov 


\title{
A Numerical Study of Anti-Vortex Film Cooling Designs at High Blowing Ratio
}

\author{
James D. Heidmann \\ National Aeronautics and Space Administration \\ Glenn Research Center \\ Cleveland, Ohio 44135
}

\begin{abstract}
A concept for mitigating the adverse effects of jet vorticity and lift-off at high blowing ratios for turbine film cooling flows has been developed and studied at NASA Glenn Research Center. This "anti-vortex" film cooling concept proposes the addition of two branched holes from each primary hole in order to produce a vorticity counter to the detrimental kidney vortices from the main jet. These vortices typically entrain hot freestream gas and are associated with jet separation from the turbine blade surface. The anti-vortex design is unique in that it requires only easily machinable round holes, unlike shaped film cooling holes and other advanced concepts. The anti-vortex film cooling hole concept has been modeled computationally for a single row of $30^{\circ}$ angled holes on a flat surface using the 3-D Navier-Stokes solver Glenn-HT. A modification of the anti-vortex concept whereby the branched holes exit adjacent to the main hole has been studied computationally for blowing ratios of 1.0 and 2.0 and at density ratios of 1.0 and 2.0. This modified concept was selected because it has shown the most promise in recent experimental studies. The computational results show that the modified design improves the film cooling effectiveness relative to the round hole baseline and previous anti-vortex cases, in confirmation of the experimental studies.
\end{abstract}

\section{Nomenclature}

$\begin{array}{ll}D R & \text { density ratio }=\rho_{c} / \rho_{i n} \\ M & \text { blowing ratio }=(\rho V)_{c} /(\rho V)_{i n} \\ \operatorname{Pr} & \text { Prandtl number } \\ \operatorname{Pr}_{t} & \text { turbulent Prandtl number } \\ R & \text { gas constant for air } \\ \operatorname{Re} & \text { Reynolds number } \\ T & \text { temperature } \\ d & \text { film cooling hole diameter } \\ k & \text { turbulence kinetic energy } \\ p & \text { film cooling hole spanwise pitch } \\ x & \text { streamwise distance from hole leading edge } \\ y & \text { transverse coordinate from hole centerline } \\ y^{+} & \text {dimensionless grid spacing } \\ z & \text { normal coordinate from wall } \\ \eta & \text { film effectiveness }=\left(T_{i n}-T_{a w}\right) /\left(T_{i n}-T_{c}\right) \\ \omega & \text { dissipation per unit turbulence kinetic energy }\end{array}$

\author{
Subscripts \\ aw adiabatic wall conditions \\ c coolant conditions \\ in freestream inlet conditions \\ $m \quad$ main hole \\ $o \quad$ no injection conditions \\ $s \quad$ side hole
}

\section{Introduction}

Film cooling is commonly used on high pressure turbine vanes and blades to enable increased turbine inlet temperatures for improved engine cycle performance. Relatively cool air is bled from the compressor to supply this film cooling flow to the turbine. However, this compressor bleed represents a loss to the system and should be minimized. There has thus been a substantial effort to reduce the film cooling flow rate required to provide the necessary cooling. Many new film cooling hole shapes and concepts have been proposed in the literature to address this issue.

Goldstein (ref. 1) provides an overview of early work in the area of film cooling for slots and discrete holes. In a gas turbine engine, slots are typically not practical, so the flow must be introduced through discrete holes. Many published studies have discussed the physics and presented data for discrete hole film cooling in various geometries. Kercher (refs. 2 and 3) presents an exhaustive list of film cooling references from the literature. The most basic film cooling geometry consists of a row of round holes in a flat plate. A typical implementation of the round hole configuration is for $30^{\circ}$ to $35^{\circ}$ holes with a pitch of $3 d$ (Pedersen, et al., (ref. 4); Foster and Lampard, (ref. 5); Pietrzyk, et al., (refs. 6 and 7); Sinha, et al., (ref. 8); Dhungel et al. (ref. 9)). This geometry allows for a study of jet lift-off behavior at various blowing ratios and is perhaps the most realistic simplified geometry for turbine film cooling. In addition, the computational study of Leylek and Zerkle (ref. 10) uses this geometry and gives an excellent description of the vortical flows associated with this geometry.

A well-known and extensively studied property of the flow from a round film cooling hole is the counter-rotating vortex pair that causes the cooling jet to separate from the surface at sufficiently high blowing ratio. This phenomenon is shown in figure 1. The counter-rotating vortex pair entrains the hot freestream gas and lifts the coolant away from the surface, drastically reducing its effectiveness. The counter-rotating 


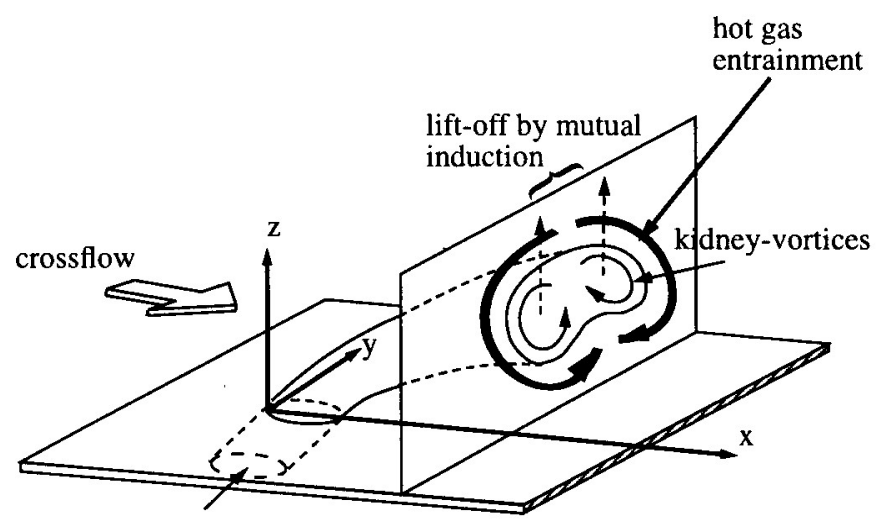

coolant

Figure 1.-Counter-rotating vortex pair and jet lift-off (from Haven et al., (ref. 11)).

vortex pair is described by Haven et al. (ref. 11) and others. Lemmon et al. (ref. 12) showed that this vorticity is caused by the bending of the jet by the freestream, and not by viscous wall effects in the hole or plenum. For cases with varying density ratio, the momentum ratio is considered to be an even better predictor of jet liftoff than blowing ratio, since higher density ratio jets will tend to remain attached to the surface at higher blowing ratios. The jet lift-off phenomenon typically occurs at momentum ratios above about 0.5 . For very low momentum ratios such as 0.25 , the circular cross-section hole produces lower vorticity levels and stays attached to the surface, providing excellent cooling. However, this momentum ratio is typically unachievable in an engine, as the available coolant pressure unavoidably produces higher coolant flow rates.

Shaped film cooling holes have typically been used to combat the jet lift-off behavior. Bunker (ref. 13) provides an excellent overview of the shaped film cooling hole literature. The primary effect of the hole shaping is to expand the exit area of the hole, thereby reducing jet velocity. However, shaped film cooling holes can be expensive to manufacture and can be limited by flow and thermal barrier coating (TBC) limitations in their expansion angles and other parameters. Many other unique film cooling designs have been proposed over the years to improve film cooling effectiveness. Besides the typical shaped hole with spanwise and/or streamwise expanded exits, various exotic hole shapes have been proposed. Ideas such as struts within the holes (Shih et al., (ref. 14)), cusp-shaped holes (Papell, (ref. 15)), triangular tabs at the hole exit (Zaman and Foss, (ref. 16)), and trenched holes (Bunker, (ref. 17)), have been proposed and studied. A common theme in these designs is the desire to offset the detrimental vorticity caused by the round hole jet. Many of the proposed designs are shown to be effective in this regard, but the majority of these ideas prove to be difficult to manufacture and/or produce unwanted features such as additional solid surfaces that must be cooled or additional sharp edges that are aerodynamic liabilities.
A recent study by Kusterer et al., (ref. 18) shows excellent cooling effectiveness for a double jet configuration similar in intent to the anti-vortex design whereby two holes are used to mitigate the jet liftoff behavior. The two jets produce a vorticity which is counter to the detrimental kidney vortices present in the single round jet. The anti-vortex concept of the present study differs from the double jet configuration in that the additional holes intersect with the main hole, which acts as a metering area for the coolant flow. The anti-vortex concept may also hold promise for turbine blades subject to plugging of the film holes due to deposition, since the hole design offers alternate paths for the coolant to exit the blade.

\section{Anti-Vortex Film Cooling Concept}

The present study proposes a new film cooling design concept which has been conceived and developed at NASA Glenn Research Center. This "anti-vortex" film cooling concept is designed to mitigate the effects of the counter-rotating vortex pair which reduces the effectiveness of circular cross-section film cooling holes at high blowing ratios. A concept studied by Heidmann and Ekkad (ref. 19) is shown in figures 2 to 4 . This implementation will be referred to as the "upstream" antivortex geometry, as the side holes emerge upstream of the main jet exit. A modified design proposed by Dhungel et al. (ref. 9) is shown in figures 5 to 7 . In this design, the side holes emerge from the surface adjacent to the main jet exit. This "adjacent" anti-vortex geometry was determined by Dhungel et al. (ref. 9) to be the best-performing anti-vortex hole shape out of a set of 6 having varying design parameters including side hole size and angle. The concept is applied in this study as a modification to a standard single row round film cooling hole arrangement with the holes angled at $30^{\circ}$ to the surface and a spanwise pitch of 3 hole diameters, and is compared to the baseline data of Dhungel et al. (ref. 9). The holes are placed in a flat plate geometry, which can be thought of as representing a turbine blade suction or pressure side film cooling hole. In the anti-vortex design, two side holes are drilled which intersect with the main hole. These side holes are angled in the spanwise direction on either side of each main hole. The geometric parameters of the two anti-vortex cases studied are shown in figure 8 and table I. For all cases, $p / d=3.0$, and the anti-vortex hole centerline intersects the main hole centerline at the bottom surface of the plate. In addition, the ratio of the side hole diameter to main hole diameter was 0.5 for all cases studied. Dhungel et al. (ref. 9) also considered a case using 0.25 for this ratio, but it was found to perform more poorly. This was likely due to an insufficient amount of coolant flow through the side holes to provide much counterrotating vorticity. A value of 1.0 might be considered in the future, especially if $p / d$ is increased to accommodate the side hole exit area increase. 


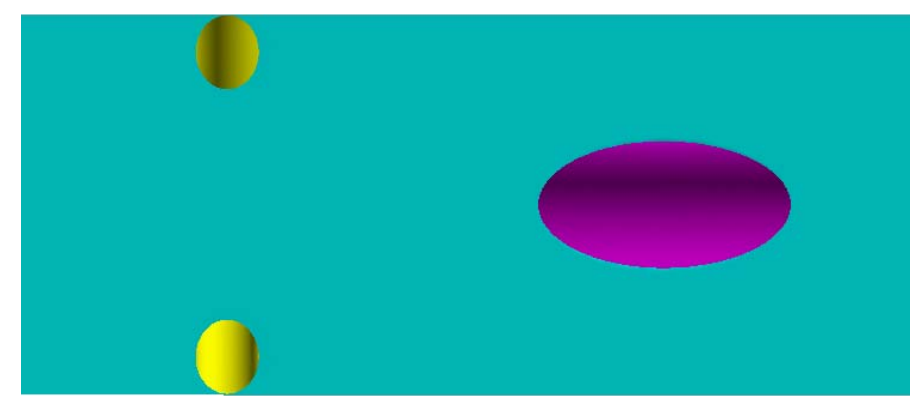

Figure 2.-Upstream anti-vortex design—top view.

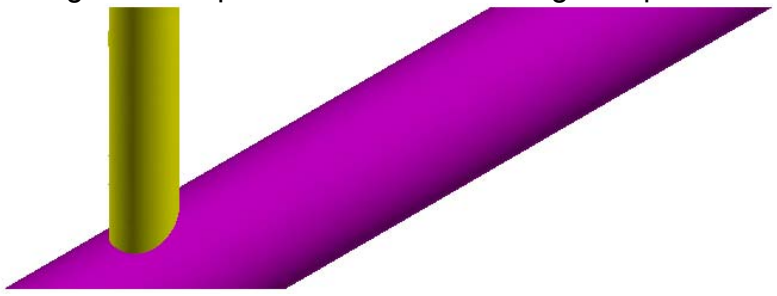

Figure 3.-Upstream anti-vortex design-side view.

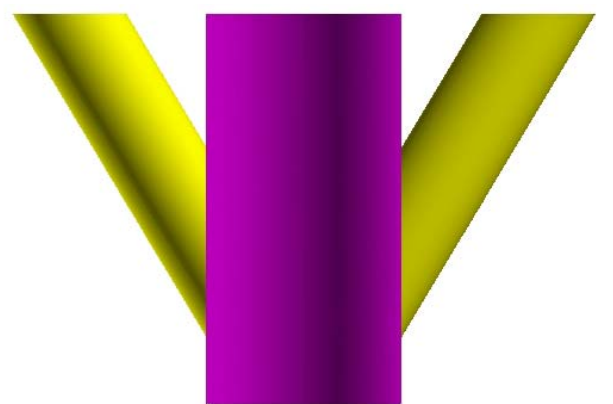

Figure 4.-Upstream anti-vortex design-front view.

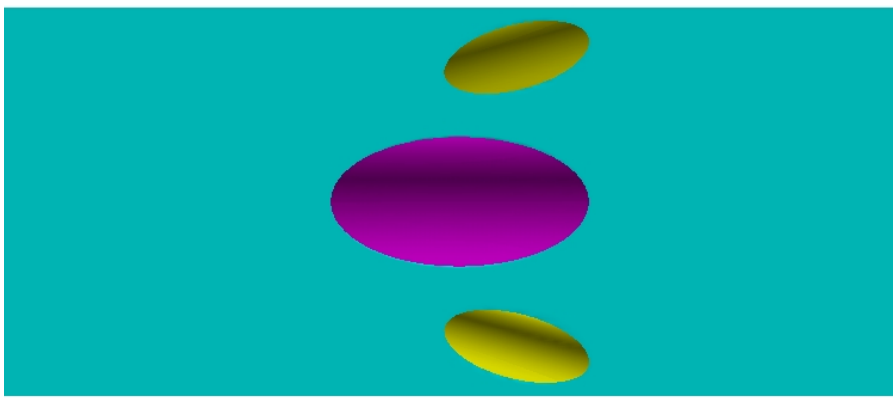

Figure 5.-Adjacent anti-vortex design—top view.

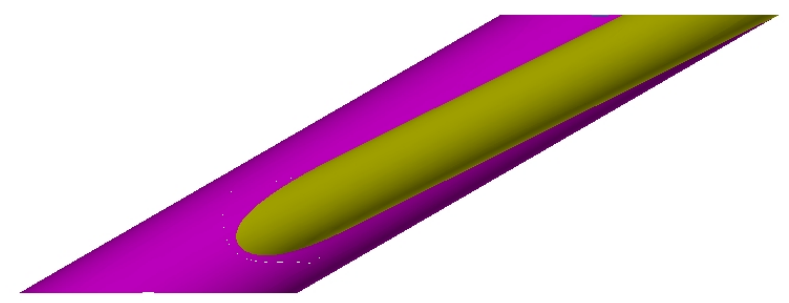

Figure 6.—Adjacent anti-vortex design—side view.

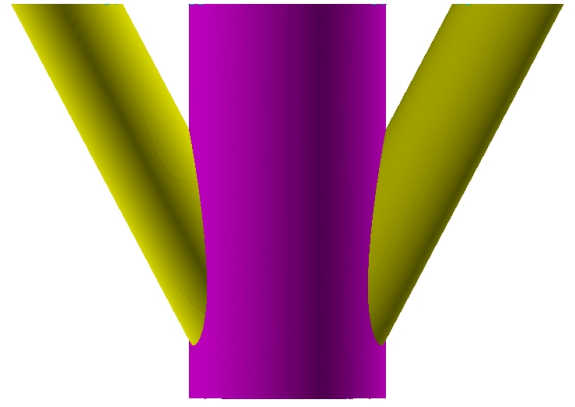

Figure 7.-Adjacent anti-vortex design—front view.

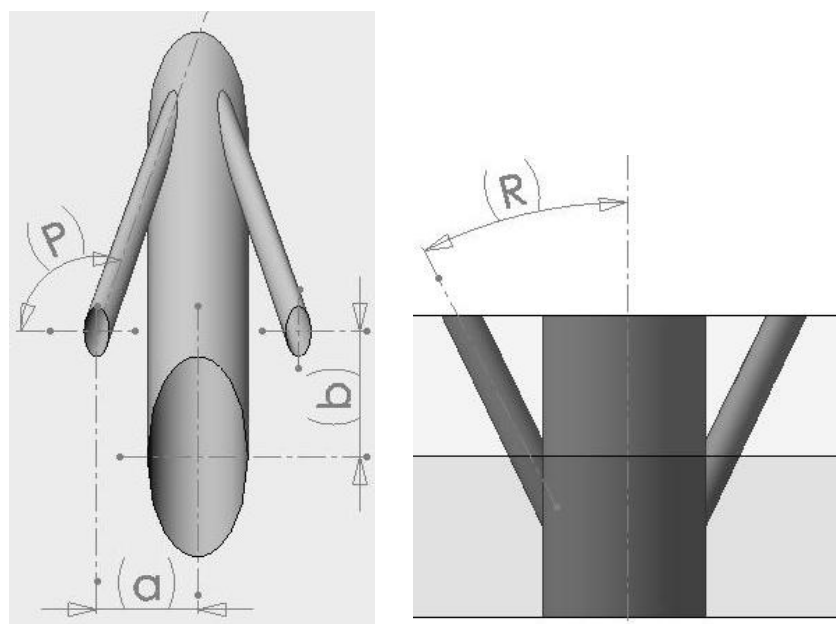

Front view

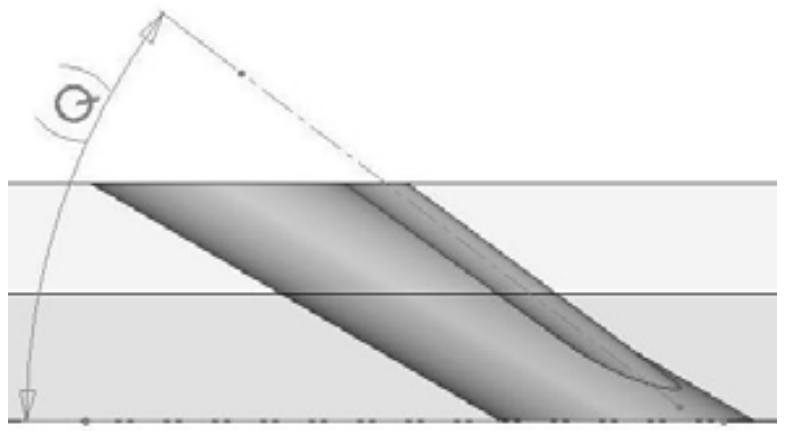

Side view

Figure 8.-Anti-vortex hole geometric parameters (from Dhungel, et al., (ref. 9)).

TABLE I.-GEOMETRIC PARAMETERS

\begin{tabular}{|c|c|c|}
\hline Case & $\begin{array}{c}\text { Upstream } \\
\text { anti-vortex }\end{array}$ & $\begin{array}{c}\text { Adjacent } \\
\text { anti-vortex }\end{array}$ \\
\hline$d_{s} / d_{m}$ & 0.5 & 0.5 \\
$a / d_{m}$ & 1.10 & 1.12 \\
$b / d_{m}$ & 3.24 & -0.44 \\
$P$ & $0^{\circ}$ & $105.67^{\circ}$ \\
$Q$ & $90^{\circ}$ & $26.41^{\circ}$ \\
$R$ & $30.62^{\circ}$ & $27.91^{\circ}$ \\
\hline
\end{tabular}


Since each main hole has a side hole on both sides, the flow from the side holes of two adjacent main holes will interact with each other, producing a strong vortex. This vortex is opposite in sense to the detrimental vorticity produced by the main hole, and is intended to force the coolant flow from the main hole to remain attached to the surface. Another way to view this expected benefit is that the side holes produce a strong upwash which must be balanced by a net downwash in the main hole jet centerline plane. There is an additional expected benefit from the side hole jet inclining away from the main jet in the spanwise direction, as this should draw the coolant from the bottom of the main jet away from the jet centerline, effectively flattening the coolant jet

There are several expected advantages to the proposed antivortex film cooling concept. Shaped holes, while they have similar effects such as reduced adverse vorticity and enhanced jet spreading, are expensive to manufacture relative to round holes which can be drilled quickly and inexpensively. Also, shaped holes do not actually cancel the adverse vorticity, but merely reduce it because of their larger exit area and reduced jet exit velocity. Shaped holes can also perform more poorly than expected if the exit velocity profile is sharply peaked and not relatively uniform as expected in the design. It is anticipated that by optimizing the anti-vortex design, a beneficial vorticity can be produced which would not only oppose the detrimental vorticity, but effectively cancel it, producing a strong flattening of the jet. Another comparison might be made to a two row staggered round film cooling hole arrangement. In this staggered arrangement, the upstream row is designed to fill in the gaps in film cooling produced by the downstream row of holes. However, for sufficiently high blowing ratios, both rows will still lift off the surface, providing very low effectiveness. Although the upstream staggered row does produce a vortex which is opposite in sense to the adjacent hole in the downstream row, this vorticity is similar in magnitude to the downstream vortex and cannot effectively cancel it. Also, the hole inlet area is doubled by adding the upstream row which will double the coolant flow rate for a given plenum pressure. The anti-vortex design, since it incorporates side holes drilled into the main hole, does not increase the hole inlet area. It has been shown by Heidmann and Ekkad (ref. 19) that the anti-vortex modification results in only a small increase in coolant flow rate for a given plenum pressure due to this metering inlet area. Also, the prior study revealed that significant flow through the side holes could only be generated when they intersect the main hole near the plenum. For this reason, both cases considered in the present study meet this condition.

One concern for the anti-vortex concept is the lower limit on the side hole diameter. This may be limited by either manufacturing or functional constraints. Bunker (ref. 13) has indicated that film cooling holes may be laser drilled to a very small size, but smaller holes are subject to plugging from particles in the coolant flow as well as by deposition of particles from the combustion air. The earlier and present studies both consider side holes half the diameter of the standard-size main hole. However, based on the very high effectiveness values predicted in the present work and examination of the coolant trajectories, it appears that on a constant overall coolant flow rate basis, it may be more effective to increase the $p / d$ value well above 3.0. The anti-vortex hole could be enlarged by a factor of two to keep the smallest hole size the same. In this case, a $p / d$ value of 6.0 would maintain the coolant hole inlet flow area and approximate coolant flow rate for a given plenum pressure. Alternatively, only the side holes could be doubled in diameter while retaining the main hole size. In this case, any increase in $p / d$ would likely result in a lower coolant mass flow per unit width. This would greatly benefit the engine cycle if adequate cooling is retained.

Another benefit of the anti-vortex concept might be their potential in turbines subject to deposition from the combustion flow, such as found in the power generation industry with the use of alternative fuels such as syngas derived from coal. The side holes offer an alternate path for the coolant to exit the blade so that the entire hole is not plugged in the case of deposition covering one of the exits.

\section{Computational Method}

Multi-block structured computational grids were produced using GridPro (Program Development Corporation) software for three geometries: baseline round holes, upstream anti-vortex, and adjacent anti-vortex. The baseline case consists of a single row of round holes at an angle of $30^{\circ}$ to the flat plate surface and a pitchto-hole diameter ratio of 3.0. The upstream anti-vortex design is from Heidmann and Ekkad (ref. 19) (figs. 2 to 4) with the side holes emerging upstream of the main jet exit. The adjacent antivortex design is from Dhungel et al. (ref. 9) (figs. 5 to 7) with the side holes exiting adjacent to the main jet. The computational domain and grid are shown in figures 9 and 10. Figure 10 highlights the grid quality near the hole intersection region for the upstream anti-vortex geometry. All grids extended from the centerline plane of the main hole to the plane midway between two adjacent main holes. Symmetry boundary conditions were applied on both of these planes. This was done since the present study was performed with a steady CFD analysis in which no flow can cross these planes because of symmetry. However, any studies using unsteady Reynolds-averaged (RANS) or large eddy simulation (LES) tools would necessitate doubling the computational domain to include an entire hole pitch and using periodic boundary conditions to allow unsteady perturbations to cross these planes.

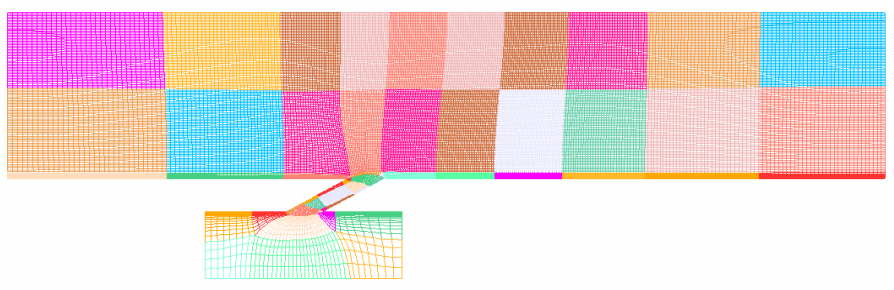

Figure 9.-Computational grid for baseline round hole case. 


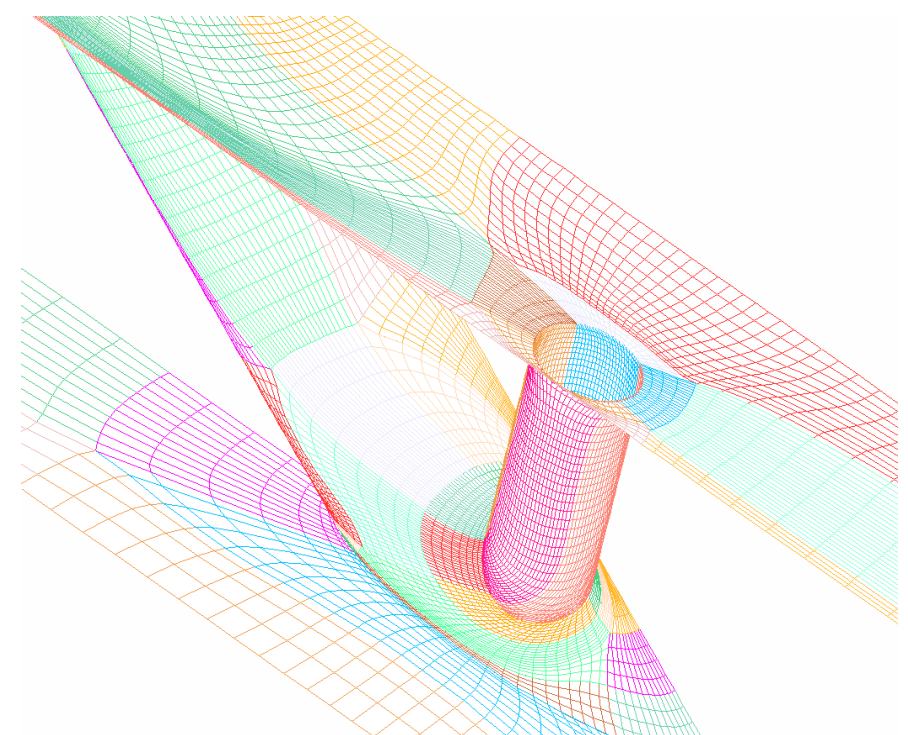

Figure 10.-Upstream anti-vortex case near-hole grid (only half of hole pitch shown).

Inflow boundary conditions were prescribed at the freestream and plenum inlet planes. Standard total pressure and total temperature values were used at the freestream inlet with flow normal to the inlet plane. The freestream inlet is 19 hole diameters upstream of the main hole leading edge. The plenum inlet total pressure was adjusted to produce the nominal blowing ratio desired. This typically produced a plenum pressure a few percent above the freestream value. It was observed that a slightly lower value of plenum pressure was required for the anti-vortex designs to produce the same blowing ratio as the baseline case. A high nominal blowing ratio of 2.0 was considered in this study, since the prior study of Heidmann and Ekkad (ref. 19) considered a blowing ratio of 1.0 and actual engines can often have blowing ratios much greater than 1.0 due to the plenum pressures required to preclude backflow into the holes. Such high blowing ratios typically produce very poor film effectiveness values for round holes and provide a challenging test case for the anti-vortex concept. The blowing ratio is defined using the inlet area of the hole, so that a given blowing ratio represents the same mass flow rate for all cases. The plenum inlet total temperature was set to either 0.95 or 0.5 times the freestream inlet total temperature. The 0.95 value was used to provide a temperature difference between the coolant and freestream for film effectiveness calculation while staying relatively close to a density ratio of 1.0 for comparison to existing data. The 0.5 value is considered representative of engine conditions. A turbulence intensity of 1.0 percent and a turbulence length scale of 1 hole diameter were specified at both inlets. The exit static pressure was set to 0.97 times the freestream inlet total pressure at the exit plane 30 hole diameters downstream of the main hole leading edge. This produced a nominal Mach number of 0.2 in the freestream. Although the large scale experiment of Dhungel et al. (ref. 9) has a lower Mach number and pressure ratio, the present conditions allow for more rapid numerical convergence while avoiding strong compressibility effects that would result from high subsonic conditions. The Reynolds number of the experiment is matched at 11300 based on hole diameter and inlet conditions. No-slip adiabatic boundary conditions were employed at all walls.

A multi-block computational grid was developed using the GridPro multiblock grid generator with approximately 2.5 million computational cells for each case. An effort was made to maintain the grid point distribution and density between cases to facilitate comparison. Results were generated for the fine grid as well as for a coarse grid solution having half the number of computational cells in each direction, or $1 / 8^{\text {th }}$ overall (about 300,000 cells). This coarse grid solution was produced using the multi-grid capability of the Glenn-HT code. Viscous clustering was employed at all solid walls with a $y^{+}$value less than 1.0 at all locations. Stretching ratios less than 1.2 were used normal to the viscous walls. Each solution on the fine grid required approximately 2000 processor-hours to converge on the in-house NASA Glenn Turbine Linux cluster, "heat". This cluster consists of 48 nodes, each with two Intel Xeon processors. Cases were typically run with 30 processors. Convergence was considered achieved when both of the following criteria had been met: 1) reduction in all residuals of three orders of magnitude, and 2) no observable change in surface temperature prediction for an additional 1000 iterations. The test cases are shown in table II. Cases in bold ( 3 to 6 and 9 to 12) are new cases. Cases 1, 2, 7 and 8 are existing cases from Heidmann and Ekkad (ref. 19), shown for completeness. Although the nominal blowing ratios were 1.0 and 2.0, there were some deviations due to the pressure inlet boundary condition. These deviations were typically within a few percent of the nominal value.

TABLE II-CALCULATION CASES

(Cases in bold (3 to 6 and 9 to 12) are new calculations)

\begin{tabular}{|c|c|c|c|l|}
\hline Case & $\begin{array}{c}\text { Density } \\
\text { ratio }\end{array}$ & $\begin{array}{c}\text { Blowing } \\
\text { ratio }\end{array}$ & $\begin{array}{c}\text { Plenum } \\
\text { pressure ratio }\end{array}$ & \multicolumn{1}{|c|}{ Geometry } \\
\hline 1 & 1.05 & 1.04 & 1.0392 & Baseline \\
2 & 1.05 & 1.01 & 1.0106 & Upstream anti-vortex \\
$\mathbf{3}$ & $\mathbf{1 . 0 5}$ & $\mathbf{1 . 0 1}$ & $\mathbf{1 . 0 3 1 0}$ & Adjacent anti-vortex \\
$\mathbf{4}$ & $\mathbf{1 . 0 5}$ & $\mathbf{2 . 0 1}$ & $\mathbf{1 . 2 0 0 0}$ & Baseline \\
$\mathbf{5}$ & $\mathbf{1 . 0 5}$ & $\mathbf{1 . 9 3}$ & $\mathbf{1 . 0 8 9 0}$ & Upstream anti-vortex \\
$\mathbf{6}$ & $\mathbf{1 . 0 5}$ & $\mathbf{2 . 0 1}$ & $\mathbf{1 . 1 7 8 5}$ & Adjacent anti-vortex \\
7 & 2.0 & 1.05 & 1.0091 & Baseline \\
8 & 2.0 & 1.02 & 0.9954 & Upstream anti-vortex \\
$\mathbf{9}$ & $\mathbf{2 . 0}$ & $\mathbf{1 . 0 3}$ & $\mathbf{1 . 0 0 3 8}$ & Adjacent anti-vortex \\
$\mathbf{1 0}$ & $\mathbf{2 . 0}$ & $\mathbf{1 . 9 9}$ & $\mathbf{1 . 0 9 2 0}$ & Baseline \\
$\mathbf{1 1}$ & $\mathbf{2 . 0}$ & $\mathbf{1 . 9 7}$ & $\mathbf{1 . 0 3 7 8}$ & Upstream anti-vortex \\
$\mathbf{1 2}$ & $\mathbf{2 . 0}$ & $\mathbf{2 . 0 4}$ & $\mathbf{1 . 0 8 6 0}$ & Adjacent anti-vortex \\
\hline
\end{tabular}

The simulations in this study were performed using the multiblock computer code Glenn-HT, previously known as TRAF3D.MB (Steinthorsson et al., (ref. 20)) which is based on a single block code designed by Arnone et al. (ref. 21). This code is a general-purpose flow solver designed for simulations of flows in complicated geometries. The code solves the full compressible Reynolds-averaged Navier-Stokes equa- 
tions using a multi-stage Runge-Kutta-based multigrid method. It uses the finite volume method to discretize the equations. The code uses central differencing together with artificial dissipation to discretize the convective terms. The overall accuracy of the code is second order. The present version of the code (Rigby et al., (ref. 22) and Ameri et al. (ref. 23)) employs the $k$ - $\omega$ turbulence model developed by Wilcox (refs. 24 and 25), with subsequent modifications by Menter (ref. 26) as implemented by Chima (ref. 27). The k- $\omega$ turbulence model is desirable because it does not require specification of distance to the wall. Such a specification is difficult for complex geometries requiring multi-block grids, such as is considered in the present study. Accurate heat transfer predictions are possible with the code because the model integrates to the walls and no wall functions are used. Rather, the computational grid is generated to be sufficiently fine near walls to produce a $y^{+}$value of less than 1.0 at the first grid point away from the wall. For heat transfer a constant value of 0.9 for turbulent Prandtl number, $\mathrm{Pr}_{t}$, is used. A constant value of $\operatorname{Pr}=0.72$ is used. Laminar viscosity is a function of temperature through a 0.7 power law (Schlichting, (ref. 28)) and $c_{p}$ is taken to be a constant.

\section{Results}

Film effectiveness for a low Mach number flow may be defined as:

$$
\eta=\left(T_{i n}-T_{a w}\right) /\left(T_{i n}-T_{c}\right)
$$

For the nominal Mach number of 0.2 in this study, the inlet temperature is very close to the compressible flow recovery temperature at the wall, and so is used in equation (1). As a check on the grid sensitivity of the study, representative calculations were carried out for both the fine grid $(\sim 2.5$ million cells) and one level of multigrid coarsening ( $\sim 300,000$ cells). There are noticeable but relatively small (typically less than 10 percent) differences between the respective coarse and fine grid results for the most stringent quantities of surface film effectiveness and heat transfer coefficient. This indicates that the fine grid is approaching grid independence. Due to the long calculation times for the fine grid cases and the extensive test matrix, the grid was not refined further in this study. All results in the following discussion are for the fine grid cases.

Table II shows the plenum pressure ratio required to yield the nominal blowing ratio for all cases. There is a moderate reduction in the pressure for the upstream anti-vortex holes, but the adjacent holes require nearly the same plenum pressure to yield the same blowing ratio and flow rate as the round holes. In other words, for a given plenum pressure, which is usually a design constraint, the adjacent anti-vortex design would yield only a very small increase in total mass flow rate, but as will be seen, produces a much higher overall effectiveness. This is in contrast to the idea of adding a second staggered row of round holes, which would nominally double the flow rate. It may be tempting to view the adjacent anti-vortex design as being simply a variation of a two-row staggered arrangement, but this mass flow distinction is an important difference, and is due to the hole throat or metering area remaining constant for all cases.

The next set of figures focus on the temperature and velocity characteristics of the three geometries for the flow conditions most representative of high blowing ratio engine conditions: $M=2$ and $D R=2$. Figures 11 to 13 show the total temperature for the baseline round hole, upstream anti-vortex,

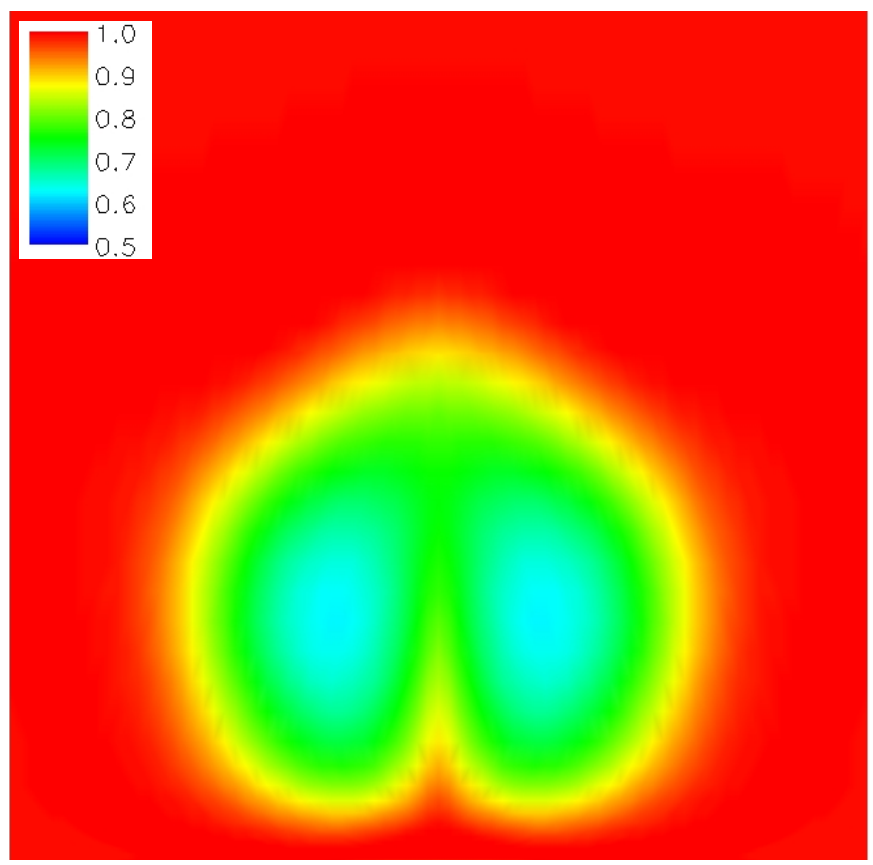

Figure 11.-Stagnation temperature $\left(T / T_{\text {in }}\right), x / d=7$, Case 10.

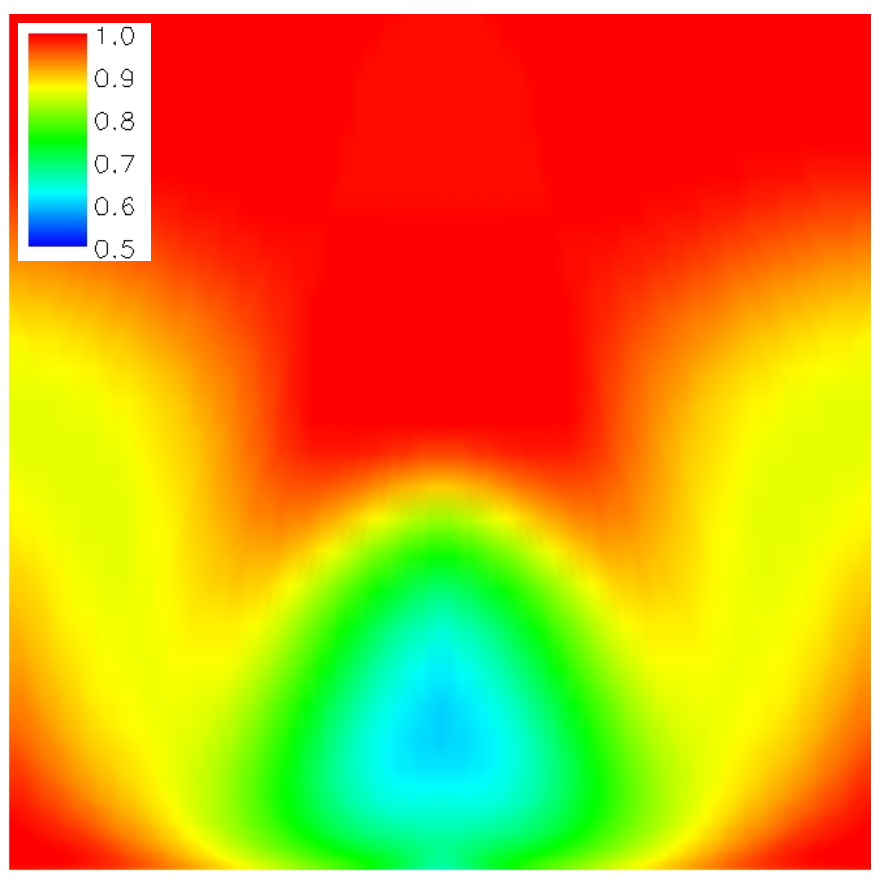

Figure 12.-Stagnation temperature $\left(T / T_{\text {in }}\right), x / d=7$, Case 11. 


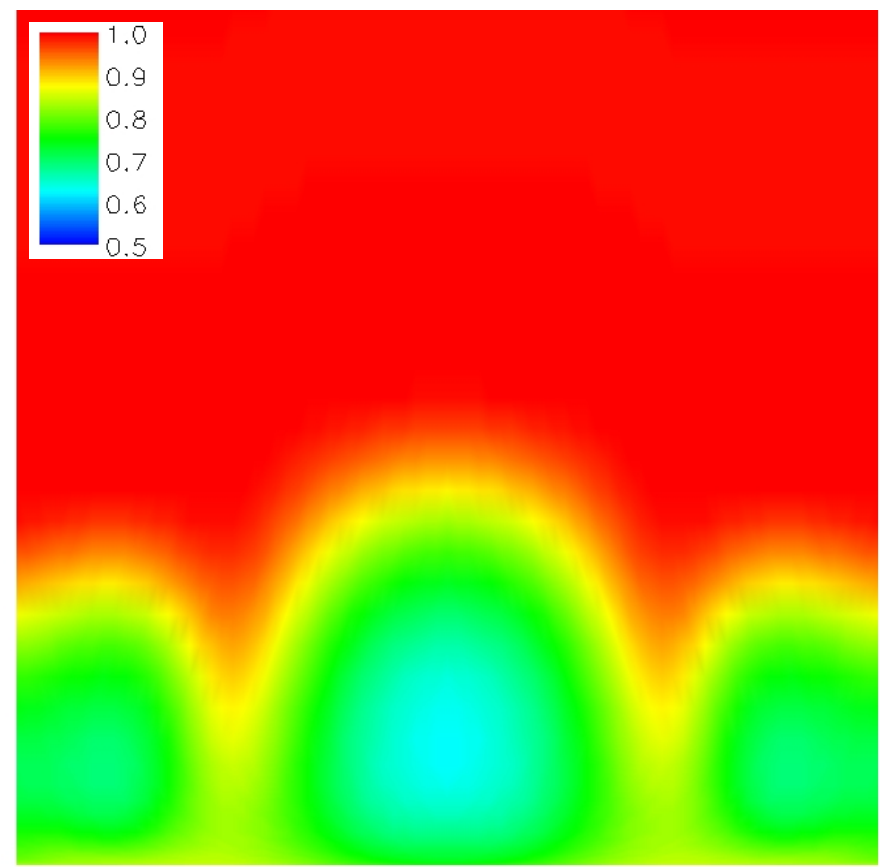

Figure 13.-Stagnation temperature $\left(T / T_{\text {in }}\right), x / d=7$, Case 12.

and adjacent anti-vortex, respectively, on a plane normal to the surface at $x / d=7$ ( 7 hole diameters from the hole leading edge or 5 hole diameters from the hole trailing edge). This streamwise location is representative of the location where film cooling jet liftoff is expected to occur for the baseline case at high momentum ratio. The calculation domain extends from the hole centerline to the mid-pitch plane-the results are mirrored about the hole centerline for display purposes. Figure 11 shows the baseline round hole jet to be fully detached at this location with the characteristic kidney vortices demonstrated. Although the $M=2, D R=2$ case is not as severe as the $M=2, D R=1$ case due to its lower density and thus momentum ratio, the effectiveness is essentially predicted to be zero at this location. Figure 12 indicates a marked improvement in wall coverage by the upstream anti-vortex concept. This corroborates the results of Heidmann and Ekkad (ref. 19) for $M=1$. However, there are still regions of the wall exposed to the hot freestream fluid. Figure 13 shows that the adjacent anti-vortex concept provides a very uniform coverage at $x / d=7$. There is no part of the wall directly exposed to the freestream temperature, and now the side hole jets are actively cooling the surface unlike the upstream anti-vortex jets, where the coolant from the side holes has migrated away from the surface.

Figures 14 to 16 show secondary flow vectors at $x / d=7$ for the same three cases as figures 11 to 13 . The vectors are colored by total temperature. Here it becomes quite apparent in figure 16 that the adjacent anti-vortex design produces a much smaller upwash velocity at the centerline of the jet. The side holes actually have a slightly larger upwash velocity than the main jet. If we consider the two side jets from adjacent

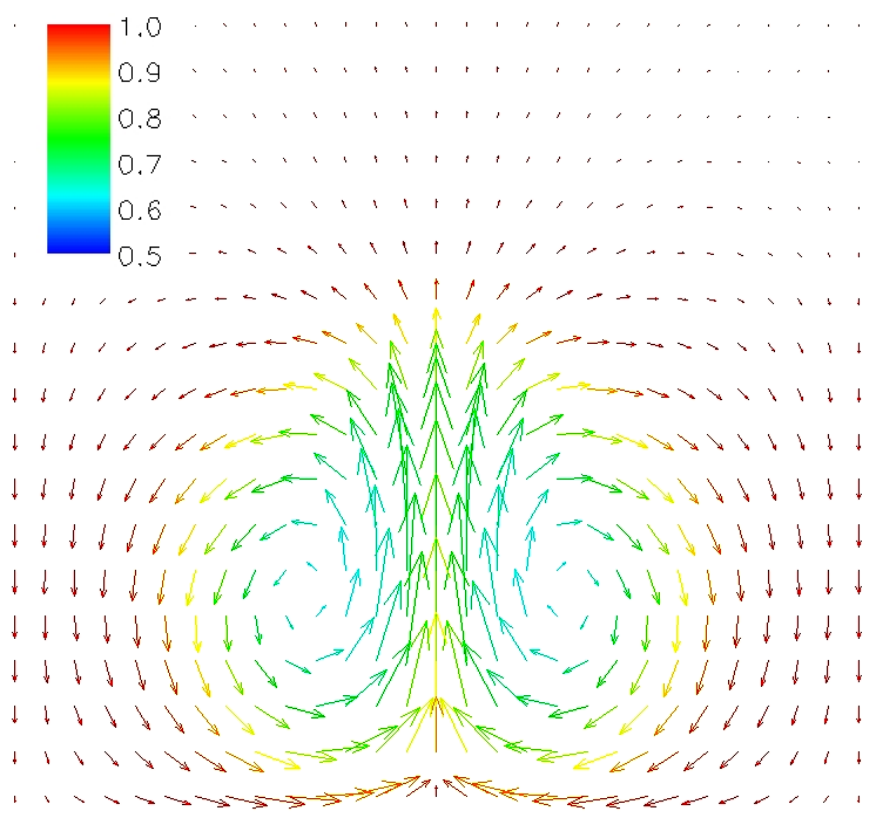

Figure 14.-Secondary flow vectors colored by temperature $\left(T / T_{\text {in }}\right), x / d=7$, Case 10

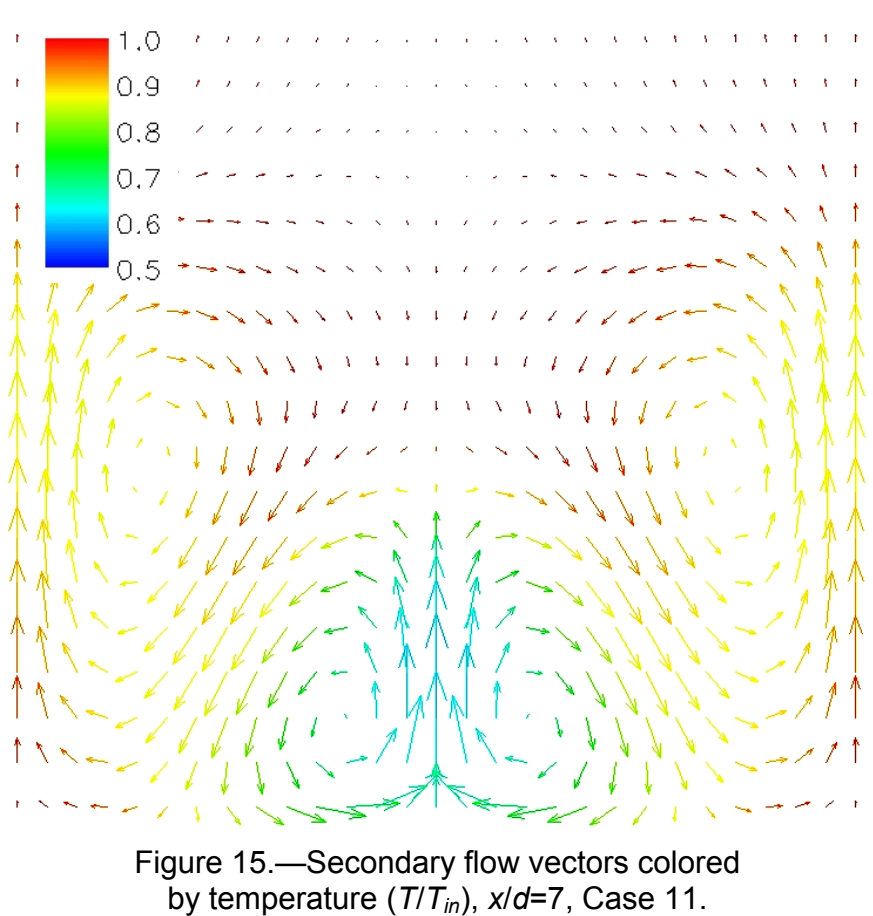

main holes, they can almost be considered a single jet with their own counter-rotating vortex pair. One of the ways to mitigate the potential for blockage of the side holes by external deposition might be to have them intersect below the blade surface, creating a larger effective opening at the surface. 

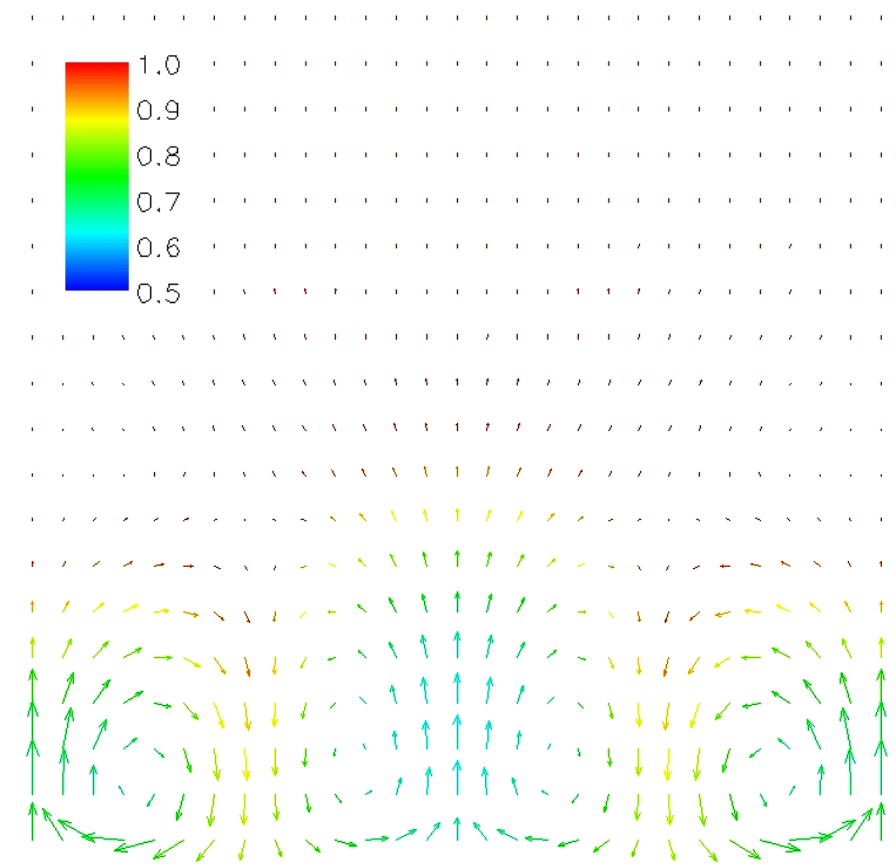

Figure 16.-Secondary flow vectors colored by temperature $\left(T / T_{\text {in }}\right), x / d=7$, Case 12 .

The earlier work of Heidmann and Ekkad (ref. 19) made an argument for the strong correlation between streamwise vorticity and film effectiveness. It is the streamwise vorticity in the round hole case that produces the jet liftoff, and the opposing vorticity of the adjacent anti-vortex jet that counteracts this behavior. Figure 17 presents the area-averaged streamwise ( $x$-component) vorticity for the three geometries at $M=2$ and $D R=2$. The vorticity is only averaged over the half-pitch computational domain, since an average over the entire mirrored region would produce zero vorticity due to symmetry. For all cases, the vorticity is zero as expected until the hole region is reached. For the baseline case, a strong negative streamwise vorticity is produced at the hole which convects downstream and reduces to about half its peak value at the end of the domain. The upstream anti-vortex design produces a large upstream vorticity at the secondary hole exit which is opposite in sense to the main hole vorticity, and almost as large in peak value. As described in Heidmann and Ekkad (ref. 19) for the $M=1$ case, the $M=2$ results show a net vorticity downstream of the main hole opposite to the round hole case. This is because although the peak value of the upstream anti-vortex vorticity is slightly smaller than the round hole, the flow bled from the upstream holes reduces the flow and associated vorticity from the main hole compared to the simple round hole. The adjacent anti-vortex hole case shows an initial negative vorticity excursion, followed by a reversion back to nearly zero net vorticity downstream by $x / d=7$. This is reflected by the contours and vectors in figures 13 and 16. It appears from this plot that the vorticity from the side holes in the adjacent anti-vortex case dissipates more slowly than the main jet vorticity, as the trend is not monotonic with increasing $x / d$.

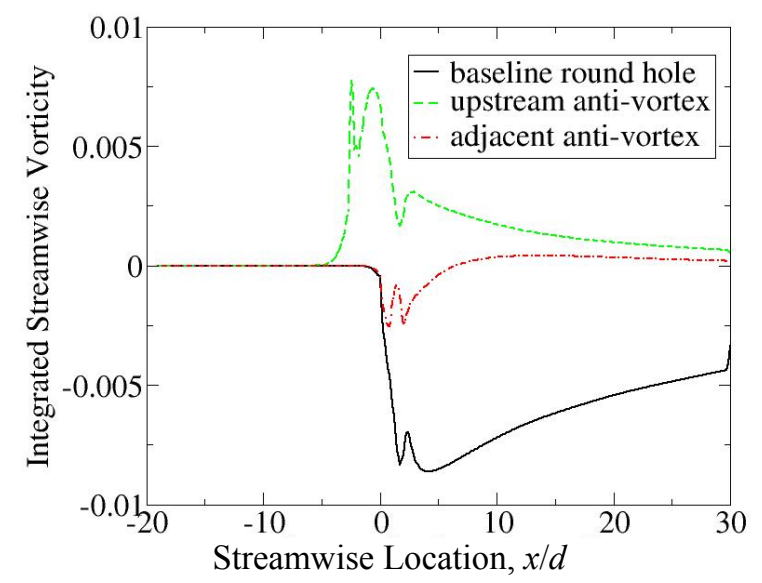

Figure 17.-Area-averaged streamwise vorticity, $M=2, D R=2$.

Table III shows the relative flow distribution between the main hole and secondary holes for each case. By definition all the flow goes through the main hole for the baseline cases. For both the anti-vortex designs, about 60 to 65 percent of the flow goes through the main hole. This correlates closely to the $2: 1$ area ratio of the holes (each main hole has two side holes each having $1 / 4$ of the main hole cross-sectional area) and derives from the fact that the holes branch from a location close to the plenum and have about the same pressure ratio across them. Since the main hole flow fractions are below $2 / 3$, there is a slightly higher effective blowing ratio through the side holes than the main hole.

TABLE III.-MAIN/SECONDARY HOLE FLOW ALLOCATION

\begin{tabular}{|c|c|l|}
\hline Case & $\begin{array}{c}\text { Percentage of total flow } \\
\text { through main hole }\end{array}$ & \multicolumn{1}{|c|}{ Geometry } \\
\hline 1 & 100 & Baseline \\
2 & 64.2 & Upstream anti-vortex \\
3 & 60.9 & Adjacent anti-vortex \\
4 & 100 & Baseline \\
5 & 60.7 & Upstream anti-vortex \\
6 & 59.1 & Adjacent anti-vortex \\
7 & 100 & Baseline \\
8 & 66.8 & Upstream anti-vortex \\
9 & 60.7 & Adjacent anti-vortex \\
10 & 100 & Baseline \\
11 & 61.9 & Upstream anti-vortex \\
12 & 59.8 & Adjacent anti-vortex \\
\hline
\end{tabular}

Figure 18 shows the predicted film effectiveness on the surface for all 12 cases, again with the results mirrored about the hole centerline for display purposes. The baseline cases all exhibit very poor effectiveness, as expected for high blowing ratios. The anti-vortex cases all produce much higher effectiveness values than their corresponding baseline. A close inspection reveals that the adjacent anti-vortex design results in better film coverage across the entire pitch, although the upstream anti-vortex cases have higher centerline values in some cases. This may be due to the fact that less coolant flow 
has been bled away from the main jet as shown in table III. The primary reason for the more uniform coverage is that the side holes in the adjacent anti-vortex case provide cooling to the surface, while the upstream holes quickly separate from the surface and serve only to curtail the lift off of the main jet.

Figures 19 to 22 are plots of span-averaged film effectiveness downstream of the main hole for all cases. $x / d=0$ is at the main hole leading edge, so the data begins at the hole trailing edge location of $x / d=2$. Each plot shows the three geometries for a given set of coolant flow parameters. The data of Dhungel et al. (ref. 9) is shown for the two $D R=1$ plots, as they did not produce data at the higher density ratio. For all cases, there is a progression in improved effectiveness from baseline to upstream to adjacent anti-vortex. The only exception to this is in figure $21(M=1, D R=2)$, where the adjacent anti-vortex film effectiveness decays more rapidly and drops below the upstream anti-vortex case near the end of the computational domain. This decay may be due to the fact that this is the case with the lowest momentum ratio (nominally 0.5 ), so there is not as strong of a vortex cancellation effect.

Figures 19 and 20 show the experimental data of Dhungel et al. (ref. 9). It can be seen that the computational predictions of effectiveness are much lower than the data, especially for the baseline case at $M=1, D R=1$ and for the baseline and upstream anti-vortex cases at $M=2, D R=1$. These are the cases where significant separation of the jet is observed in the calculations, and the underprediction of film effectiveness under these circumstances is well-documented. The trends, however, are consistent, as the incremental improvement predicted for the three geometries is borne out in the data. In fact, the predictions for the adjacent anti-vortex concept are reasonable, as would be expected for predictions for fully-attached jets with blowing ratios of about 0.5 or less. There is a difference in the trend of film effectiveness with increasing $x / d$, especially in figure 20. The experimental data shows a gradual reduction in film effectiveness with streamwise distance, while the CFD predicts a gradual increase. This may be attributed to the fact that the CFD solutions predict a more discrete, coherent jet than the actual case, where presumably the unsteady mixing causes the jet to be more spread out and diffuse. If this is the case, the cold fluid in the coherent CFD jet would continuously provide fresh, cold fluid to the surface as the flow proceeds downstream, resulting in an increase in effectiveness with $x / d$. This points to the need for better flowfield data for corroboration of this type of argument.

It has been shown in previous work that detached eddy simulations (DES) (Kapadia et al., (ref. 29)) are better able to predict the complex mixing processes inherent in high blowing ratio cases, and thereby result in better agreement with film effectiveness data compared to steady RANS simulations such as in the present study. At least some of this difference is thought to be due to the enhanced unsteady mixing which occurs in a high blowing ratio jet, which can only be resolved in an unsteady calculation. This mixing actually results in higher film effectiveness values due to the convection of coolant back to the surface in what otherwise would be a

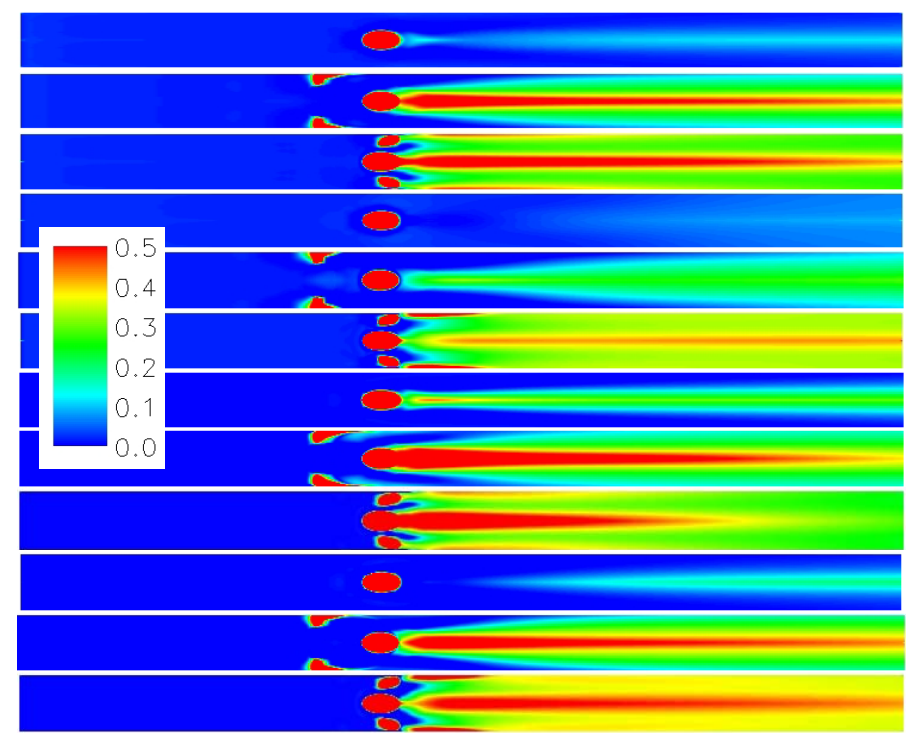

Figure 18.-Film effectiveness, $\eta$, Cases 1 to 12.

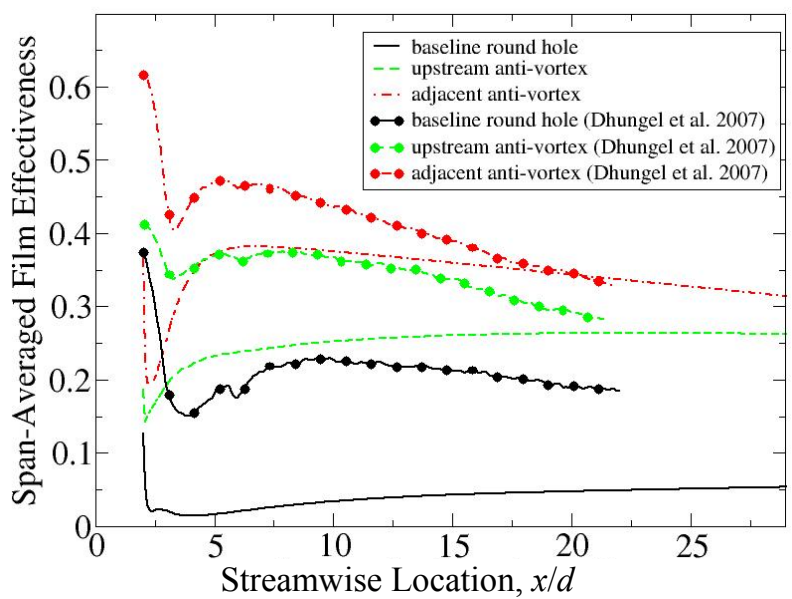

Figure 19.-Span-averaged film effectiveness, $M=1, D R=1$.

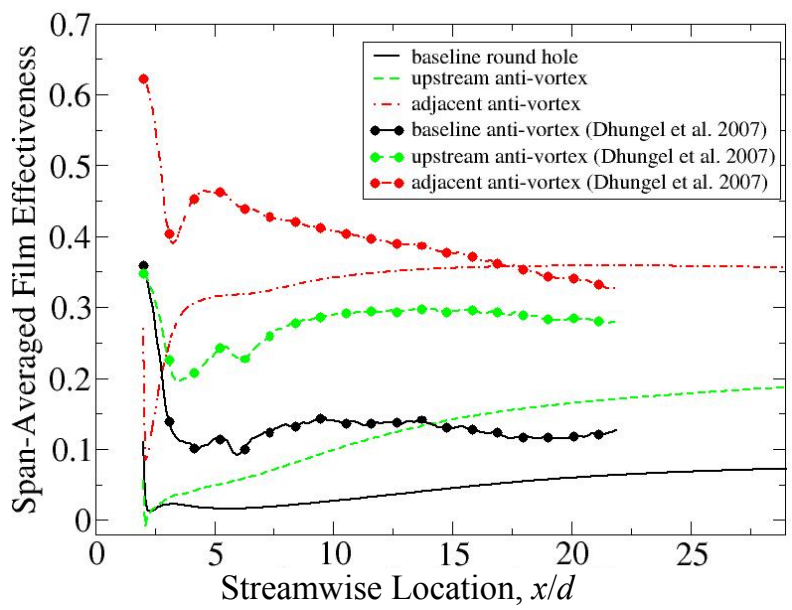

Figure 20.-Span-averaged film effectiveness, $M=2, D R=1$. 


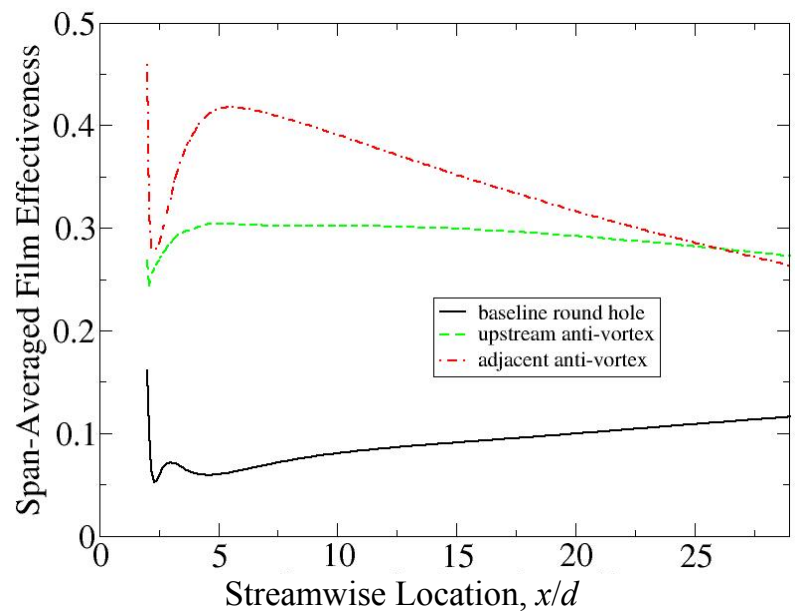

Figure 21.-Span-averaged film effectiveness, $M=1, D R=2$.

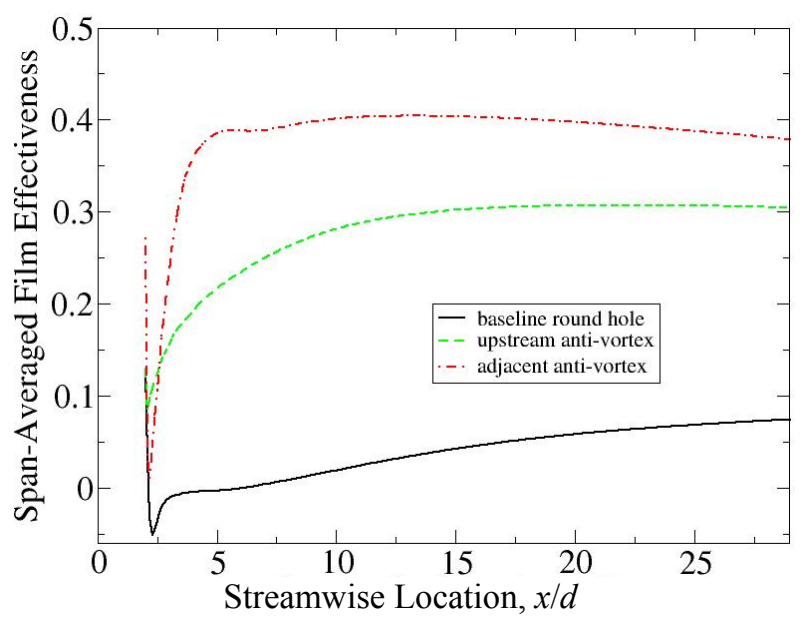

Figure 22.-Span-averaged film effectiveness, $M=2, D R=2$.

completely detached jet of very low effectiveness such as seen in these steady RANS calculations. However, due to the intensive computational requirements for such an unsteady calculation, steady RANS calculations are still preferred for studying large sets of cases as in the present study. It would again be useful to obtain detailed unsteady flowfield data for high blowing ratio film cooling jets to help develop and validate better models for steady RANS codes for these cases.

Table IV gives area-averaged values of film effectiveness for all cases. The averaging is done over the entire spanwise width and from $x=2$ (the main hole trailing edge) to $x=30$ (the end of the computational domain). The film effectiveness values are reflective of the span-averaged results already described. While the upstream anti-vortex cases have some variability in their area-averaged effectiveness, the adjacent anti-vortex cases demonstrate remarkable consistency in their values for the four coolant flow conditions. This indicates that the adjacent anti-vortex design should confer some benefit with regard to reduced sensitivity to local flow conditions on the turbine blade surface. It should be noted that the large improvement in film effectiveness seen in this study for the adjacent anti-vortex design is comparable to the improvement afforded by the use of shaped holes. This was demonstrated in the experimental data of Dhungel et al. (ref. 9), where the adjacent anti-vortex film effectiveness was comparable to the shaped hole value and even a bit higher at the highest blowing ratio of 2.0. Of course the anti-vortex concept has the additional benefit of geometric simplicity. To get a complete picture of the thermal performance of the various cases, it would be necessary to additionally run cases with a wall heat flux to generate heat transfer coefficient distributions and net heat flux reduction values. This was not done in the present study.

TABLE IV.-AREA-AVERAGED EFFECTIVENESS

\begin{tabular}{|c|c|c|}
\hline Case & $\eta$ & Geometry \\
\hline 1 & 0.040 & Baseline \\
2 & 0.252 & Upstream anti-vortex \\
3 & 0.345 & Adjacent anti-vortex \\
4 & 0.048 & Baseline \\
5 & 0.129 & Upstream anti-vortex \\
6 & 0.339 & Adjacent anti-vortex \\
7 & 0.091 & Baseline \\
8 & 0.292 & Upstream anti-vortex \\
9 & 0.339 & Adjacent anti-vortex \\
10 & 0.039 & Baseline \\
11 & 0.279 & Upstream anti-vortex \\
12 & 0.381 & Adjacent anti-vortex \\
\hline
\end{tabular}

\section{Summary and Conclusions}

A novel "anti-vortex" film cooling design concept has been conceived and designed at NASA Glenn Research Center. The present study extends prior work by Heidmann and Ekkad (ref. 19) to higher blowing ratios and density ratios representative of actual engine conditions. An improvement to the original anti-vortex design suggested by Dhungel et al. (ref. 9) has also been studied under these conditions and computational results have been compared with the data. Although there are discrepancies between the computational results and experimental data, especially for detached jet cases, the general trend is well-predicted. In agreement with the data of Dhungel et al. (ref. 9), the adjacent anti-vortex concept improves the film effectiveness beyond the upstream anti-vortex concept by about an additional 50 percent above the improvement afforded by the upstream concept alone. This translates to a full 0.3 improvement in area-averaged film effectiveness for the adjacent anti-vortex concept versus the baseline hole for all conditions.

Based on the results of this study, it is proposed that increasing $p / d$ and increasing the side hole diameter should be the next geometry evaluated. This would provide benefit for a number of reasons. First, the increased $p / d$ would reduce the overall coolant flow while presumably retaining most of the jet spreading 
benefit. With a larger $p / d$, there would also be more room to enlarge the side holes to the same size as the main hole, alleviating concerns about plugging of them from particles in the flow. Additionally, the larger $p / d$ would facilitate a larger inclination angle of the side holes in the spanwise direction, increasing the anti-vortex effect. Finally, such a geometry with the larger side holes would provide a cooling design that is less sensitive to deposition effects such as those encountered where coal-derived fuels are used in the combustor.

Another recommendation is to address the need for highly detailed unsteady flowfield experimental data for high blowing ratio film cooling holes. This data could then be used to develop and validate models for steady RANS codes that are better able to predict the jet/mainstream interaction and resulting surface film effectiveness values that current steady RANS models cannot.

\section{References}

1. Goldstein, R.J., 1971, Film Cooling, Advances in Heat Transfer, vol. 7, pp. 321-379.

2. Kercher, D.M., 1998, "A Film-Cooling CFD Bibliography: 19711996," International J. of Rotating Machinery, 4, no. 1, pp. 61-72.

3. Kercher, D.M., 2000, "Turbine Airfoil Leading Edge Film Cooling Bibliography: 1972-1998," International Journal of Rotating Machinery, 6, no. 5, pp. 313-319.

4. Pedersen, D.R., Eckert, E.R.G., and Goldstein, R.J., 1977, "Film Cooling With Large Density Differences Between the Mainstream and the Secondary Fluid Measured by the Heat-Mass Transfer Analogy," Journal of Heat Transfer, vol. 99, pp. 620-627.

5. Foster, N.W. and Lampard, D., 1980, "The Flow and Film Cooling Effectiveness Following Injection Through a Row of Holes," Journal of Engineering for Power, vol. 102, pp. 584-588.

6. Pietrzyk, J.R., Bogard, D.G., and Crawford, M.E., 1989, "Hydrodynamic Measurements of Jets in Crossflow for Gas Turbine Film Cooling Applications," Journal of Turbomachinery, vol. 111, pp. 139-145.

7. Pietrzyk, J.R., Bogard, D.G., and Crawford, M.E., 1990, "Effects of Density Ratio on the Hydrodynamics of Film Cooling," Journal of Turbomachinery, vol. 112, pp. 437-443.

8. Sinha, A.K., Bogard, D.G., and Crawford, M.E., 1991, "FilmCooling Effectiveness Downstream of a Single Row of Holes with Variable Density Ratio," Journal of Turbomachinery, vol. 113, pp. 442-449.

9. Dhungel, S., Phillips, A., Ekkad, S.V., and Heidmann, J.D., 2007, "Experimental Investigation of a Novel Anti-Vortex Film Cooling Hole Design," ASME Paper GT2007-27419.

10. Leylek, J.H., and Zerkle, R.D., 1994, "Discrete-Jet Film Cooling: A Comparison of Computational Results With Experiments," Journal of Turbomachinery, vol. 116, pp. 358-368.
11. Haven, B.A., Yamagata, D.K., Kurosaka, M., Yamawaki, S., and Maya, T., 1997, "Anti-Kidney Pair of Vortices in Shaped Holes and Their Influence on Film Cooling Effectiveness," ASME Paper 97 GT-45.

12. Lemmon, C.A., Kohli, A., and Thole, K.A., 1999, "Formation of Counter-Rotating Vortices in Film-Cooling Flows," ASME Paper 99-GT-161.

13. Bunker, R.S., 2005, "A Review of Shaped Hole Turbine FilmCooling Technology," Journal of Heat Transfer, vol. 127, pp. 441-453.

14. Shih, T.I.-P., Lin, Y.-L., Chyu, M.K., and Gogineni, S., 1999, "Computations of Film Cooling from Holes with Struts," ASME Paper 99-GT-282.

15. Papell, S.S., 1984, "Vortex Generating Flow Passage Design for Increased Film-Cooling Effectiveness and Surface Coverage," Presented at the 22nd Natl. Heat Transfer Conf., Niagara Falls, N.Y., 5-8 Aug. 1984

16. Zaman, K.B.M.Q. and Foss, J.K., 1997, "The Effects of Vortex Generators on a Jet in Crossflow," Physics of Fluids, vol. 9, pp. 106-114.

17. Bunker, R.S., 2002, "Film Cooling Effectiveness Due to Discrete Holes within a Transverse Surface Slot," ASME Paper GT-200230178 .

18. Heidmann, J.D. and Ekkad, S.V., 2008, "A Novel Antivortex Turbine Film-Cooling Hole Concept," Journal of Turbomachinery, vol. 130, no. 3, July 2008 (in press) and ASME Paper GT200727528.

19. Steinthorsson, E., Liou, M.-S., and Povinelli, L.A., 1993, "Development of an Explicit Multiblock/Multigrid Flow Solver for Viscous Flows in Complex Geometries," AIAA Paper 93-2380.

20. Arnone, A., Liou, M.-S., and Povinelli, L.A., 1991, "Multigrid Calculation of Three-Dimensional Viscous Cascade Flows," AIAA Paper 91-3238.

21. Rigby, D.L., Ameri, A.A., and Steinthorsson, E., 1997, "Numerical Prediction of Heat Transfer in a Channel with Ribs and Bleed," ASME Paper 97-GT-431.

22. Ameri, A.A., Steinthorsson, E., and Rigby, D.L., 1997, "Effect of Squealer Tip on Rotor Heat Transfer and Efficiency," ASME Paper 97-GT-128.

23. Wilcox, D.C., 1994, Turbulence Modeling for CFD, DCW Industries, Inc., LaCanada, CA.

24. Wilcox, D.C., 1994, "Simulation of Transition with a Two-Equation Turbulence Model," AIAA Journal, vol. 32, no. 2, pp. 247-255.

25. Menter, F.R., 1993, "Zonal Two-Equation k- $\omega$ Turbulence Models for Aerodynamic Flows," AIAA Paper 93-2906.

26. Chima, R.V., 1996, "A k- $\omega$ Turbulence Model for Quasi-ThreeDimensional Turbomachinery Flows," NASA TM-107051.

27. Schlichting, H., 1979, Boundary Layer Theory, McGraw-Hill, New York, $7^{\text {th }}$ edition, pp. 312-313.

28. Kapadia, S., Roy S. and Heidmann, J., 2004, "First Hybrid Turbulence Modeling for Turbine Blade Cooling" Journal of Thermophysics and Heat Transfer, vol. 18, Number 1, pp. 154-156. 


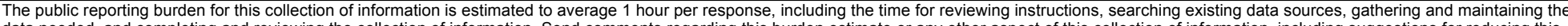

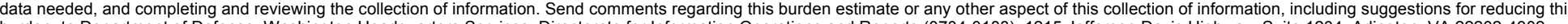

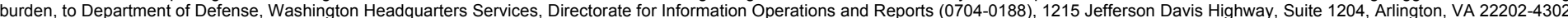

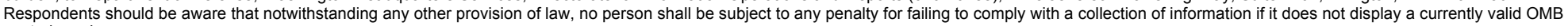
control number.

control number.
PLEASE DO NOT RETURN YOUR FORM TO THE ABOVE ADDRESS

\section{REPORT DATE (DD-MM-YYYY) \\ 2. REPORT TYPE \\ 3. DATES COVERED (From - To)}

01-11-2008

\section{TITLE AND SUBTITLE}

Technical Memorandum

A Numerical Study of Anti-Vortex Film Cooling Designs at High Blowing Ratio

\section{5a. CONTRACT NUMBER}

5b. GRANT NUMBER

5c. PROGRAM ELEMENT NUMBER

6. AUTHOR(S)

Heidmann, James, D.

\section{5d. PROJECT NUMBER}

5e. TASK NUMBER

5f. WORK UNIT NUMBER

WBS 561581.02.08.03.21.02

8. PERFORMING ORGANIZATION

REPORT NUMBER

E-16482

National Aeronautics and Space Administration

John H. Glenn Research Center at Lewis Field

Cleveland, Ohio 44135-3191

\section{SPONSORING/MONITORING AGENCY NAME(S) AND ADDRESS(ES)}

National Aeronautics and Space Administration

Washington, DC 20546-0001

\begin{tabular}{l}
$\begin{array}{l}\text { 10. SPONSORING/MONITORS } \\
\text { ACRONYM(S) } \\
\text { NASA }\end{array}$ \\
\hline $\begin{array}{l}\text { 11. SPONSORING/MONITORING } \\
\text { REPORT NUMBER } \\
\text { NASA/TM-2008-215209; GT2008-50845 }\end{array}$
\end{tabular}

\section{DISTRIBUTION/AVAILABILITY STATEMENT}

Unclassified-Unlimited

Subject Categories: 07 and 34

Available electronically at http://gltrs.grc.nasa.gov

This publication is available from the NASA Center for AeroSpace Information, 301-621-0390

\section{SUPPLEMENTARY NOTES}

\section{ABSTRACT}

A concept for mitigating the adverse effects of jet vorticity and liftoff at high blowing ratios for turbine film cooling flows has been developed and studied at NASA Glenn Research Center. This "anti-vortex" film cooling concept proposes the addition of two branched holes from each primary hole in order to produce a vorticity counter to the detrimental kidney vortices from the main jet. These vortices typically entrain hot freestream gas and are associated with jet separation from the turbine blade surface. The anti-vortex design is unique in that it requires only easily machinable round holes, unlike shaped film cooling holes and other advanced concepts. The anti-vortex film cooling hole concept has been modeled computationally for a single row of $30^{\circ}$ angled holes on a flat surface using the 3D Navier-Stokes solver Glenn-HT. A modification of the anti-vortex concept whereby the branched holes exit adjacent to the main hole has been studied computationally for blowing ratios of 1.0 and 2.0 and at density ratios of 1.0 and 2.0. This modified concept was selected because it has shown the most promise in recent experimental studies. The computational results show that the modified design improves the film cooling effectiveness relative to the round hole baseline and previous anti-vortex cases, in confirmation of the experimental studies

\section{SUBJECT TERMS}

Turbine; Film cooling; Heat transfer

\begin{tabular}{|c|c|c|c|}
\hline \multicolumn{3}{|c|}{ 16. SECURITY CLASSIFICATION OF: } & $\begin{array}{l}\text { 17. LIMITATION OF } \\
\text { ABSTRACT }\end{array}$ \\
\hline $\begin{array}{l}\text { a. REPORT } \\
\text { U }\end{array}$ & $\begin{array}{l}\text { b. ABSTRACT } \\
\mathrm{U}\end{array}$ & $\begin{array}{l}\text { c. THIS } \\
\text { PAGE } \\
U\end{array}$ & UU \\
\hline
\end{tabular}

18. NUMBER
OF
PAGES
17

19a. NAME OF RESPONSIBLE PERSON

STI Help Desk (email:help@sti.nasa.gov) 19b. TELEPHONE NUMBER (include area code) 301-621-0390 

